\title{
PROYECTO GENOMA HUMANO VISTO DESDE EL PENSAMIENTO DE LA COMPLEJIDAD. IMPLICACIONES BIOÉTICAS
}

\begin{abstract}
Sonia R. Sánchez González*
Resumen: En este trabajo se entrega una visión desde el pensamiento de la complejidad acerca de las implicaciones sistémicas de la manipulación del genoma humano. La evolución es el proceso central de la biología que nos ayuda a comprender la diversidad del mundo vivo. Hoy se quiere imponer el determinismo genético, sin tener en cuenta que los seres humanos son, además de su dotación genética, producto de la interacción con su medio, tanto biológico como social. Si bien puede resultar de gran beneficio para la humanidad, la manipulación del genoma humano puede ser utilizada con fines discriminatorios y de dominación, además de lo imprevisible de las consecuencias debido a las propiedades emergentes que resultarían de cada procedimiento.
\end{abstract}

Palabras clave: propiedades emergentes, pensamiento de la complejidad

\section{THE HUMAN GENOME PROJECT SEEN FROM COMPLEXITY THEORY. BIOETHICAL IMPLICATIONS}

\begin{abstract}
In this work, a vision is proposed from a complexity viewpoint about the systematic implications of human genome manipulation. Evolution is the central biological process that helps us understand the diversity of the living world. Today, it is held as the prevalent viewpoint without taking into account that human beings are, in addition to their genetic endowment, products of interaction with their surroundings, as much biological as social. Although it can be of great benefit to humanity, the manipulation of the human genome can also be utilized for discriminatory ends and domination, besides the unforeseeable consequences due to the emergent properties that result from each procedure.
\end{abstract}

Key words: emergent properties, complexity theory

\section{PROJETO GENOMA HUMANO VISTO SOB A ÓTICA DO PENSAMENTO DA COMPLEXIDADE. IMPLICAÇÓES BIOÉTICAS}

Resumo: Neste trabalho se oferece uma visão a partir do pensamento da complexidade acerca das implicaçôes sistêmicas da manipulação do genoma humano. A evolução é o processo central da biologia que nos ajuda a compreender a diversidade do mundo vivo. Hoje se quer impor o determinismo genético, sem levar em conta que os seres humanos são, além de sua dotação genética, produto da interação com o seu meio, tanto biológico como social. Ainda que possa resultar num grande beneficio para a humanidade, a manipulação do genoma humano poderá ser utilizada com finalidades discriminatórias e de dominação, ademais da imprevisibilidade das conseqüências devido às propriedades emergentes que resultariam de cada procedimento.

Palavras-chave: propriedades emergentes, pensamento da complexidade

\footnotetext{
Profesora del Instituto Superior de Ciencias Médicas de La Habana. Facultad de Ciencias Médicas "Victoria de Girón", Cuba Correspondencia: sonia.sanchez@infomed.sld.cu
} 


\section{Introducción}

La evolución de los organismos vivos se remonta a más de tres mil millones de ańos y podemos afirmar que todos estos organismos comparten un pasado común. Las culturas politeístas atribuyen a cada elemento un espíritu interior que los habita y les proporciona su propia dinámica, lo que conocemos como "animismo". Las religiones monoteístas, como el islamismo, el judaísmo y el cristianismo, consideran que sólo los organismos vivos y especialmente los humanos poseen voluntad propia. Descubrimientos como el de William Harvey (1578-1647), sobre la circulación de la sangre, sentaron el precedente de una visión mecanicista del mundo que tuvo su máximo exponente en Isaac Newton (16421727). Esta percepción de los procesos biológicos y del funcionamiento del cuerpo humano aún prevalece en nuestros días(1).

La filosofía de Descartes representa el punto de madurez inicial del pensamiento moderno. La filosofía cartesiana es continuación de los esfuerzos anteriores y a la vez radical innovación. Para Descartes, ninguna verdad puede ser conocida a menos que sea inmediatamente evidente. Pero la evidencia, como único criterio admisible, debe poseer las notas de claridad y distinción. Es necesario descomponer toda cuestión en sus elementos últimos y más sencillos, y reconstruirla para la prueba con los mismos elementos, es decir, con sus mismas y primarias evidencias. Descartes abonó el terreno para una investigación científica de la naturaleza construida según las leyes matemáticas divinas. La materia, cuerpo y naturaleza podían, a diferencia del pensamiento y el sentimiento, ser cuantificados, examinados $y$, en última instancia, comprendidos mediante la física matemática(2).

La licencia cartesiana de una visión del mundo reduccionista, lineal y disciplinar permitió al intelecto humano penetrar por medio de la ciencia en muchos dominios diferentes, de lo muy pequeño a lo muy grande y hasta lo invisible, y descubrir las más intrincadas relaciones de la materia. Hasta hoy anima a los científicos a estudiar un universo abierto a la investigación.

Con las nuevas tecnologías la ciencia ha puesto al descubierto los más intrincados procesos de la materia viva. En 1953 el físico inglés Francis Crick y el biólogo norteamericano James $\mathrm{D}$. Watson describen la molécula de ADN. No necesitan patentar su aporte al conoci- miento humano, la comunidad científica y el mundo en general; tal vez sin poder predecir aún el alcance que tendría este descubrimiento, le otorgan un lugar privilegiado en la memoria colectiva. Pero el micromundo celular guarda innumerables sorpresas y el dogma del concepto de flujo de información unidireccional desde el $\mathrm{ADN}$ a la proteína se desmorona cuando en 1970 se descubre la transcriptasa inversa, capaz de convertir ARN en una copia de ADN. Esto para dejar bien sentado que no podemos afirmar con absoluta certeza que sabemos todo acerca de los complejos mecanismos que se llevan a cabo intracelularmente.

A mitad de la década de los 80 el debate sobre la posibilidad de caracterizar todo el genoma humano, en lo que se refiere a su composición de nucleótidos, comenzó en serio. En 1990 se inició el Proyecto Genoma Humano, PGH (Human Genome Proyect, HGP). Consistía en varios proyectos genómicos individuales en todo el mundo y sus objetivos eran identificar las 3.000 megabases $(\mathrm{Mb})$ de la secuencia de ADN humano, localizar los más o menos 50000 genes y construir mapas físicos y genéticos detallados(3). Con estas investigaciones se han abierto infinitas posibilidades para el desarrollo ulterior de las ciencias biomédicas en beneficio de la salud humana, aunque todo parece indicar que pueden devenir en un sentido utilitarista y mercantilista, sin evaluar además las posibles consecuencias que las manipulaciones del genoma pueden ocasionar a la existencia misma de la vida.

Es evidente la escasa capacidad de los seres humanos para anticipar las consecuencias de sus acciones. El calentamiento global, las especies extinguidas y en extinción, el hambre de miles seres humanos mientras en muchos lugares se desechan los alimentos, las enfermedades que emergen producto de la contaminación ambiental y el uso indiscriminado de medicamentos, la desertificación, la contaminación de las aguas, la injusticia, la discriminación y las grandes diferencias entre los países más ricos y los más pobres, son un doloroso ejemplo. Nos enfrentamos además a la incertidumbre del uso que se le dará a los resultados obtenidos en las investigaciones del PGH, las cuales se realizan sin considerar que la célula es un sistema complejo y, por tanto, en estrecha relación con su entorno; que la vida es una propiedad emergente y que el ser humano no es una suma de reacciones moleculares.

En este artículo se argumentará que los sistemas complejos son impredecibles y que cualquier manipulación 
del genoma humano puede derivar en peligrosas consecuencias, tanto para el desarrollo individual como para la humanidad. Se desarrollarán los aspectos más actualizados sobre el pensamiento de la complejidad, referidos a la visión sistémica de la vida, las características de la célula como sistema complejo y la impredecibilidad de las consecuencias de la manipulación del genoma humano.

\section{De un mundo lineal, disciplinar y reduccionista hacia el paradigma de la complejidad}

Desde Aristóteles, considerado el primer biólogo de la tradición occidental, hasta la actualidad, la visión del mundo ha ido cambiando en la medida en que se han explorado nuevos campos y se han obtenido nuevos resultados(4).

Hasta los siglos XVI y XVII existía la visión de un mundo viviente y espiritual basada en la filosofía aristotélica y en la teología cristiana, pero la revolución científica propiciada por los descubrimientos en las matemáticas y física, y relacionada con los nombres de Galileo, Newton y Descartes, llevó a considerar al mundo como una máquina. En la biología, el descubrimiento de William Harvey sobre la circulación sanguínea respondía a las exigencias de los postulados mecanicistas de Descartes.

No fue hasta el siglo XVIII cuando Antoine Lavoisier descubrió la respiración como un proceso de oxidación que comprende procesos químicos en el funcionamiento de los organismos vivos. El movimiento romántico marcó una vuelta a la tradición aristotélica y Goethe -una de las figuras cimeras de este movimiento- elaboró importantes conceptos como el de "morfología", útil aún para el estudio de la forma biológica desde una perspectiva dinámica y del desarrollo. Por otro lado, Khan se convertía en el primero en utilizar el término autoorganización para definir la naturaleza de los seres vivos(4).

El naturalista alemán Alexander von Humboldt consideró el clima como una fuerza global unificadora y admitió la coevolución de organismos vivos, clima y corteza terrestre, lo que abarca casi en su totalidad la hipótesis de Gaia(1).

El siglo XIX se caracterizó por un notable desarrollo del conocimiento, como la formulación de la teoría de Rudolph Virchow, que llevó la atención desde los organismos a la célula y su funcionamiento interno; el desarrollo de la microbiología por Luis Pasteur, que condujo también a una visión reduccionista al considerar las bacterias como única causa de enfermedad; el descubrimiento de las leyes de la herencia genética y la introducción del concepto de homeóstasis, adelantado por Claude Bernard.

Después de un largo proceso, vitalistas y organicistas se opusieron a que la biología fuera reducida a física o química: el comportamiento de un organismo como un todo integrado no puede ser comprendido únicamente desde el estudio de sus partes, ya que las propiedades emergentes que caracterizan al organismo no pueden ser explicadas sólo a partir de las propiedades asociadas a sus partes. A principios del siglo XX Ross Harrison introdujo el concepto de organización, propiciando un cambio desde el pensamiento mecanicista al sistémico. El bioquímico Lawrence Henderson usó el término "sistema" para denominar organismos vivos y sistemas sociales(4). "Sistema" es un todo integrado cuyas propiedades esenciales surgen de las relaciones entre sus partes y "pensamiento sistémico" la comprensión de un fenómeno en el contexto de un todo superior. El pensamiento sistémico tiene las siguientes características(4):

- Los sistemas vivos son totalidades integradas, cuyas propiedades no pueden ser reducidas a las de sus partes más pequeñas.

- Las propiedades del sistema quedan destruidas cuando éste se disecciona en sus elementos aislados.

- Cada nivel se expresa con un grado de complejidad.

- En cada nivel se expresan las propiedades sistémicas que reciben el nombre de "propiedades emergentes".

- Las propiedades de las partes sólo pueden entenderse desde el contexto del todo mayor, esto es, el pensamiento sistémico es contextual. Como esto significa la explicación en términos de entorno, podemos afirmar que el pensamiento sistémico es un pensamiento medioambientalista.

- El pensamiento sistémico siempre es un pensamiento procesal, enfatizado por primera vez por el biólogo Ludwig Von Bertalanffy. Por ejemplo, el metabolismo de una célula involucra miles de reacciones químicas producidas simultáneamente para transformar los nutrientes, sintetizar las estructuras básicas y eliminar los productos de desecho. El 
metabolismo es una actividad continua, compleja y altamente organizada.

- Los sistemas abiertos se mantienen estables lejos del equilibrio o lo que se denomina equilibrio dinámico.

- Los sistemas se autorregulan.

- Las propiedades sistémicas son propiedades de un patrón.

- El mundo viviente se presenta como sistemas dentro de sistemas, lo que permite percibir la interconexión en red de todos los elementos.

El proceso evolutivo descrito por Darwin se remonta a millones de años. Desde las primeras biomoléculas hasta los organismos pluricelulares, a través de la selección natural, prevalecen los organismos mejor adaptados al medio. Hoy se consideran cuatro grandes fuerzas evolutivas: las mutaciones, la deriva génica, la transferencia de genes y la selección natural. Muchos científicos, continuadores de la herencia darwiniana, sustentan que la vida evoluciona mediante variación genética aleatoria; existe sin embargo un número cada vez mayor que considera que cada vez que aparece una nueva forma de vida no se parte de cero, sino que toda nueva complejidad es producto de la interacción de organismos preexistentes, resultado de mutaciones aleatorias y perpetuados los más aptos por la selección natural(1).

Para Morin las propiedades emergentes son producidas por la organización del sistema y están ligadas a las ideas de cualidad, globalidad y novedad. La cualidad que surge se produce por la organización del sistema, que es mucho más que la suma de sus componentes. Es irreductible e indeducible(5).

Uno de los estudios más representativos de esta interacción la realizó el científico inglés J. E. Lovelock sobre la composición de gases de la atmósfera y su relación con los protistas y bacterias (la flora intestinal), productoras de metano y presentes en el rumen de las vacas(1).

Estos y otros trabajos realizados posteriormente llevan hoy a considerar que la vida es mucho más que organismos independientes. Individuos antes autosuficientes pasan a formar parte de entidades mayores, la mayor de las cuales es la biosfera misma. De esta manera se cumple con la Segunda Ley de la Termodinámica (Nicolás Carnot, 1796-1832), que establece que en cualquier sistema cambiante la entropía aumenta y se libera en forma de calor, ruido, etc.; pero a medida que los pequeños sistemas pierden calor el universo lo gana. El premio Nobel belga Ilya Prigogine(1) plantea que la vida pertenece a una clase más amplia de estructuras disipativas (importan formas útiles de energía y exportan formas menos útiles) que incluyen centros de actividad no vivos como remolinos, tornados, etc. Otra cualidad imprescindible de la vida es el automantenimiento, la autopoiesis(6). Ese continuo flujo de energía, característico de las células, los organismos y la biosfera.

Las células son sistemas complejos y, como tales, se autorregulan, se mantienen atrapados al borde o límite del caos, presentan alternancia de determinismo e indeterminismo, tienen infinitas trayectorias en un volumen finito, presentan propiedades fractales, establecen redes de interacción no lineales que intercambian información, masa, energía y sentido con el entorno(7). La red optimiza la conectividad entre sus componentes y propicia óptima capacidad de procesar información y sentido. Los sistemas complejos son autopoieticos, se reproducen y poseen una amplia gama de alternativas para cambiar. El ADN es una molécula capaz de autoreproducirse, pero no de automantenerse, no es autopoiética, existe y funciona en un entorno que es la célula, la menor unidad autopoiética que existe. Ésta, a su vez, depende del medio en el cual se desarrolla y así, de manera sucesiva, existen redes de redes de interacciones no lineales que permiten la conectividad entre todos los elementos abióticos y bióticos de la naturaleza. De los sistemas complejos emergen propiedades como resultado de la transición a un nuevo estado alejado del equilibrio en el cual se mantienen.

\section{Terapia génica $(3)$}

Podemos definir la terapia génica (TG) como el tratamiento de una enfermedad a través de la manipulación genética. Esto incluye, por ejemplo, el tratamiento del hipotiroidismo con hormonas tiroideas o el suministro de esteroides para reducir la inflamación en el asma. Ellos traen como consecuencia la inducción, represión, estimulación o inhibición de diferentes genes en distintos tejidos del organismo. La novedad fundamental es la introducción en el individuo de nuevo material genético. La TG de células somáticas pretende tratar un individuo y quizás a un solo órgano de esa persona sin afectar sus células germinales, pero este es un aspecto que no se puede asegurar y al cual los investigadores no se refieren. En enfermedades monogenéticas las perspectivas son realmente muy desfavorables, con ex- 
cepción hasta el momento de la fenilcetonuria (trastorno autosómico recesivo caracterizado por la no conversión de la fenilalanina en tirosina debido a un defecto de la enzima fenilalanina hidroxilasa, causa de retraso mental e hipopigmentación), la cual se puede controlar con una dieta adecuada libre de fenilalanina. El resto de los pacientes tiene expectativas de vida muy desfavorables; los tratamientos actuales garantizan que la vida se acerque a lo normal en solo $15 \%$ de los casos, lo cual habla a favor del uso de estas técnicas. Una enfermedad en la cual se han obtenido resultados muy alentadores es en la deficiencia de adenosina desaminasa (ADA), defecto autosómico recesivo que produce una carencia de esta enzima; esto ocasiona la acumulación de ATP (trifosfato de adenosina), especialmente en los linfocitos $T$, dando como resultado inmunodeficiencia combinada grave que se recaracteriza por infecciones bacterianas, virales y micóticas recurrentes con diarrea y muerte precoz.

A pesar de la investigación exhaustiva y del conocimiento que se acumula a diario sobre la biología molecular de la célula y la transferencia de genes, los dos problemas técnicos a los que se enfrenta la TG son el suministro de $\mathrm{ADN}$ a la célula y el control de la expresión de ese ADN una vez que está dentro de la célula. Entre los tipos de TG que se contemplan actualmente están la suplementación génica, la supresión génica, los métodos negativos dominantes, la destrucción autolítica y la transferencia génica. La terapia génica tiene como objetivo tratar los defectos monogénicos, neoplasias e infecciones. Entre las enfermedades candidatas a ser tratadas por TG se encuentran la Hemoglobinopatía, Fenilcetonuria, Trastornos del ciclo de la urea, Hemofilia $A+B$, Hipercolesterolemia familiar y la Distrofia de Duchenne. Millones de años de evolución se han encargado de que el único material genético intracelular que viva sea el del huésped y es un problema que la célula acepte el $\mathrm{ADN}$ extraño y lo mantenga intacto. En general, las células no toleran $\mathrm{ADN}$ que no sea parte de sus cromosomas; éste se degrada, se elimina o se pierde durante la división.

En la TG de línea germinal, todas las células del organismo presentan su composición genética alterada, porque los gametos femeninos y masculinos -dígase óvulo y espermatozoide- han sido genéticamente alterados y, por tanto, estas alteraciones pasarán a la nueva descendencia (posibilidad cierta de ser utilizada con fines perfeccionistas de los caracteres de un individuo -dígase inteligencia, estatura, etc.). La terapia génica y las pruebas diagnósticas deben realizarse evaluando los posibles riesgos y beneficios, con el fin de prevenir, diagnosticar y tratar los problemas de salud factibles de ser tratados, siempre con fines de beneficencia, no maleficencia, justicia y equidad.

\section{Algunas contradicciones}

La Declaración Universal sobre el Genoma Humano y los Derechos Humanos(8-10) desaconseja la clonación y las intervenciones en óvulos y espermatozoides. También plantea que el genoma humano es patrimonio común de la humanidad. Sin embargo, en Estados Unidos ya se han concedido patentes a secuencias génicas(8-10). Los médicos y hospitales que deseen utilizar los genes para fines diagnósticos deben pagar a los dueños cada vez que utilicen estas secuencias. Las grandes empresas farmacéuticas esperan recuperar, multiplicadas en varias veces, las inversiones realizadas en las investigaciones del Proyecto Genoma Humano.

\section{Conclusiones}

La manipulación del genoma humano es un esfuerzo encomiable para mejorar la salud de las personas y un resultado de gran importancia para la humanidad. Si bien el estudio de la naturaleza fragmentada en pequeñas partes y las condiciones de frontera impuestas a cada experimento han permitido un gran desarrollo de las diferentes ramas del saber y aportado conocimiento acerca del funcionamiento de los seres vivos, la humanidad se enfrenta a graves problemas como consecuencia de una visión reduccionista y lineal de los procesos naturales.

Vista hoy desde el pensamiento de la complejidad, la vida se muestra como el comportamiento emergente de la sustancia y la energía. Las características individuales no vienen dadas solamente por la información genética que existe en el individuo, sino también por el entorno, tanto naturaleza como sociedad, en el cual se desarrolla el ser humano, que va desde sus condiciones de vida hasta la biosfera como un todo. Considerar que un ser humano está definido por sus genes es perder de vista la espiritualidad, los sentimientos, la conciencia que caracterizan a la especie humana. Es reducirnos sencillamente a interacciones moleculares dejando a un lado la condición humana que se forma sobre todo en condiciones específicas de interacción con el ambiente. 


\section{Referencias}

1. Lyn M, Sagan D. ¿Qué es la vida? Barcelona: Tusquets; 1996.

2. Abbagnano N. Historia de la Filosofía. Cuba: Ciencias Sociales; 1971: 103.

3. Cox T. y Sinclair J. Biología Molecular. En: Medicina. Espańa: Panamericana; 1998: 103-336.

4. Fritfof C. La trama de la vida. Una nueva perspectiva de los sistemas vivos. Barcelona: Anagrama; 1999.

5. Morin E. El método. La naturaleza de la naturaleza. España: Cátedra; 2001.

6. Maturana H, Varela F. El árbol del conocimiento. Las bases biológicas del entendimiento humano. Santiago de Chile: Universitaria, 1972: 19-163.

7. Sotolongo PL. Los presupuestos y las implicaciones filosóficas del pensamiento de la complejidad y de las ciencias de la complejidad. La Habana: Cátedra de Complejidad, Instituto de Filosofía, Academia de Ciencias de Cuba; 2007.

8. Santos y Vargas L. Valuación bioética del Proyecto Genoma Humano. Acta Bioethica 2000; 8(1).

9. Rodríguez Yunta E. Ética de la investigación en genética humana. En: Lolas F, Quezada A, Rodríguez E, (eds.) Investigación en salud. Dimensión ética. Santiago de Chile: CIEB, Universidad de Chile; 2006.

10. Chneinweiss $\mathrm{H}$. El patentamiento de genes: un instrumento jurídico vinculado a la ciencia y la ética. En: Bioética. Compromiso de todos. Montevideo: Facultad de Ciencias, Trilce; 2003.

Recibido: 25 de febrero de 2008

Aceptado: 13 de abril de 2008 